\title{
Experience towards Simulated Patient-based Simulation Session: An Integrative Literature Review
}

Accepted: 01-07-2019

Online: $31-10-2019$

\author{
Goh Lay-Khim, Yee Bit-Lian² \\ ${ }^{1}$ Clinical Skills and Simulation Centre, International Medical \\ University Malaysia, Kuala Lumpur, MALAYSIA \\ ${ }^{2}$ Cluster of Applied Science, Open University Malaysia, \\ Kuala Lumpur, MALAYSIA
}

To cite this article: Goh L-K, Yee B-L. Experience towards simulated patient-based simulation session: an integrative literature review. Education in Medicine Journal. 2019;11(3):5-21. https://doi. org/10.21315/eimj2019.11.3.2

To link to this article: https://doi.org/10.21315/eimj2019.11.3.2

\begin{abstract}
Simulated patient $(\mathrm{SP})$ is defined as a layperson who simulates to portray the role of a patient with health-related conditions based on varying levels of training. SP allows students to practice various skills under guided experience in a realistic, safe, and controlled setting. The purpose of this integrative review is to examine original research relating to the experience towards simulated patient-based simulation session. A rapid review included three electronic databases search of articles published between 2008 to 2018 with inclusive and exclusive criteria. Seventeen articles were eventually selected for inclusion in the review. These articles were subjected to basic thematic analysis. Descriptive analysis of the study design, study location, professional area, and study variables were reported. Six themes were identified: SP's perspective, evaluation of SP's performance, euthenticity of SP role play, SP feedback, student's development, and evaluation of student's performance. SP methodology has been widely used to train healthcare students in the development of medical knowledge, clinical skills, as well as important soft skills. SPs, students, and facilitators play a role to ensure the success of an SP-based simulation session. The outcome of the training with SP was examined through an assessment of either the student's performance or the SP's performance. The outcome of the review concluded that SPs' development indirectly influences students' development.
\end{abstract}

Keywords: Experience, Simulated patient, Simulated patient programme, Simulation Lumpur, Wilayah Persekutuan Kuala Lumpur, Malaysia | E-mail: yeebl@oum.edu.my

\section{BACKGROUND}

Simulated patient (SP) is defined as a trained individual who portrays the role of a patient with various health associated conditions. The term SP also refers to a healthy individual trained to portray a patient. Another definition has described $\mathrm{SP}$ as a layperson who simulates as a real patient based on differing levels of training
(1-3). Combining these descriptions, SP can be defined as a layperson who simulates to portray the role of a patient with healthrelated conditions based on varying levels of training.

SP can be interchangeably used with role player, trained patient, patient instructor, and actor-patient. SP can also play a variety of roles along the educational path for 
health sciences students as well as training of hospital staffs, such as clinical teaching associate, incognito or unannounced patient, volunteer patient, hybrid patient, and confederate (2).

There are nine roles of SP: (a) role player; (b) trained patient; (c) patient instructor; (d) actor patient; (e) clinical teaching associate; (f) incognito or unannounced patient; (g) volunteer patient; (h) hybrid patient; and (i) confederate. Role player refers to the individuals who portray as the patient who often are medical, nursing or health professional students. Trained patient concerns a person who may or may not use their experience of certain diseases to play his/her role. The Patient instructor is commonly used in the medical programme and means the individual is a real patient and can be directed to use his/ her own history and physical exam findings to portray a patient. Actor patient refers to a professional actor acting as a patient. Clinical teaching associate are SPs trained to teach specific physical examination such as breast, rectal, and vaginal. The teaching focus is on supporting the students to develop psychomotor, communication, and other professional skills. SP who pretend as a real patient and enter the real clinical setting with permission to judge clinical performance are addressed as Incognito or unannounced patient. Volunteer patient is the person who is insufficiently healthy to attend teaching sessions. The role of this patient usually involves role-play activities in Objective Structured Clinical Examination (OSCE). The patient involved in the use of a combination of real human and simulator mimicking a real environment for the practice of procedural and operative skills is a hybrid patient. Lastly, confederate means an individual other than the patient who is scripted to provide realism, additional challenges or additional information for the students. For example, paramedic, receptionist, family member, laboratory technician, and the voice of manikins (2).
SP has been reportedly used in addressing communication skills, physical examination skills, safe manual handling and personal care assistance, and hybrid simulation for invasive procedures (4). By practicing with SPs, students have the opportunity to develop various skills such as patient interview skills, assessment skills, team collaboration, professionalism, patient education skills, interpersonal skills, clinical skills, ethical decision making, patient safety, and communication skills. SP can portray both physical and behavioural issue with and without the presence of medical conditions for the students to learn under guided experience in a realistic, safe, and controlled setting rather than 'practicing on' potentially distressed and vulnerable patients in reallife consultations (3-5). The purpose of this article is to review research relating to the experience of the simulated patient-based simulation session.

\section{METHOD}

\section{Data Selection}

\section{Search strategy}

The researcher began the search process with mind-mapping of research keywords - simulated patient, simulated patient programme, and simulated patient programme experience - with the aim to analyse available research related to simulated patient programme and experience towards simulated patient or simulated patient programme. These three keywords were searched within three electronic databases, i.e. Google Scholar, Open University Library, and BioMed Central (BMC). The search initially returned a high volume of articles; therefore, an advanced search was performed by filtering the year and keyword search in title only. 


\section{Study selection}

This review considered multiple research methods, including pilot study, descriptive qualitative, descriptive quantitative, correlation, regression analyses, and literature and systemic review. Articles written in English, peer-viewed, and associated to SP based simulation session related to education training were included from 2008 to 2018 (10 years) to explore a wider range of data.

\section{Data extraction}

Initially, a high volume of results was achieved within the BMC search. The researcher then did manual screening of the title for relevant articles. After the initial scanning of title, 56 articles were selected for the next screening, which was reading abstract through the application of inclusion and exclusion criteria as shown in Table 1. This resulted in 44 studies selected for the full-text reading. Full review of these 44 studies resulted in 17 articles that was included in the present review. The study and selection process flow chart is illustrated in Figure 1.

Legend: A total of 344 papers were identified through three electronic databases, i.e. BMC, Google Scholar, and Open University Library. Six articles were excluded due to duplication. Next, 338 papers were screened for title and abstract

Table 1: Inclusive and exclusive criteria

\begin{tabular}{ll}
\hline Inclusive criteria & Exclusive criteria \\
\hline 1. Study focuses on SP based simulation & 1. Study focuses on SP based simulation session \\
$\quad$ session related to education training. & not related to education training. \\
2. Peer reviewed. & 2. Duplication. \\
3. Year 2008 to year 2018. & 3. Concept paper. \\
4. All study design including reviews. & 4. Non-English language. \\
5. English language. & \\
\hline
\end{tabular}

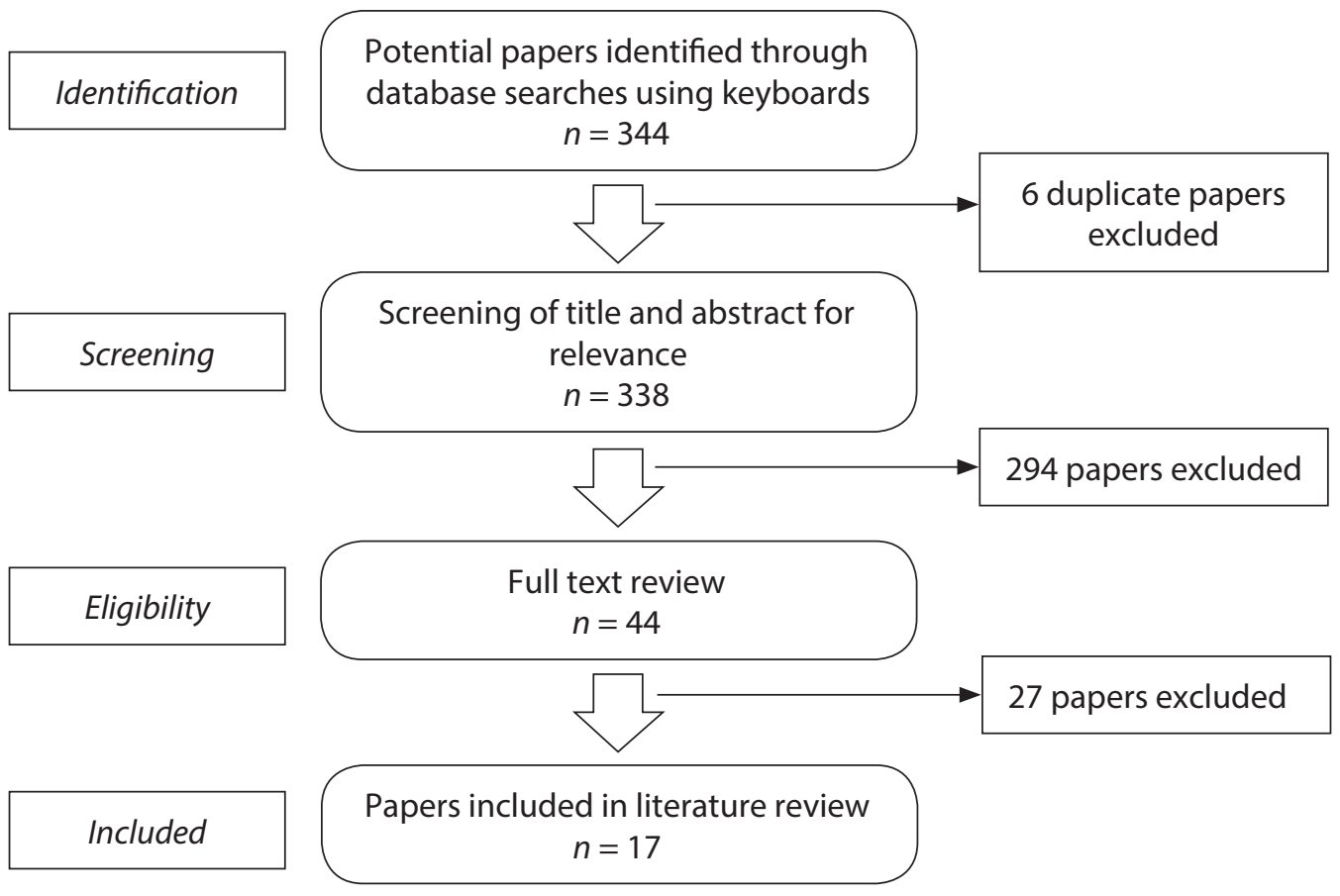

Figure 1: Study and selection process flow chart 
relevance and 294 studies were excluded due to content not focused on SP based simulation session related to education training and duplication. Finally, 44 papers were eligible for full-text review and 27 articles were further excluded due to content not focused on SP based simulation session related to education training. Therefore, the remaining 17 articles were included in the review.

\section{RESULTS}

\section{Study Design}

Of a total of 17 articles were included in this literature review; the majority (eight) were mixed method, five were descriptive and comparison quantitative study design, one qualitative (case study), one randomised control trial, one scooping review, and one systemic review.

\section{Study Location}

Most of the studies were conducted in a European country (9 out of 17), including United Kingdom (three), Netherlands (two), Norway (two), Denmark (one), and Germany (one), while the rest were undertaken in other countries such as Australia (four), Canada (one), and interestingly one study was conducted in Malaysia. Two research studies were conducted across a few countries, in which each study involved four countries Scotland, Netherlands, Republic of Ireland, and Belgium, and Australia, Canada, Switzerland, and United Kingdom.

\section{Professional Area}

Majority of the studies' outcome contributed to medical education (13 out of 17), in which 12 studies focused on undergraduate medical education, while one study focused on postgraduate medical education, while the remaining three studies were multidisciplinary and one study focused on speech-language pathology education.

\section{Study Variable}

Most of the studies focused on SP (10 out of 17), while the rest on students (three) and lecturer (one). Three articles had more than one variable (a combination of SP, student and/or lecturer) examined.

The full list of the studies selected for inclusion in this literature review is presented in Table 2, including the authors, study location, sample of the study, study purpose(s), study design, and the research findings.

\section{Synthesis}

All studies were analysed numerous times to obtain an overall sense of data. Content that stood out as meaningful was identified and utilised as the basis for theme formation. The literature review identified six key themes: (a) SP's perspective; (b) evaluation of SP's performance; (c) authenticity of SP role play; (d) SP feedback; (e) student's development; and ( $f$ ) evaluation of student's performance. The prevalence of themes within each article is illustrated in Table 3.

\section{SPs' perspective}

Three studies examined the participants' experience in SP work (6-8). All three studies agreed that the positive impact by participating as an SP included the development of knowledge, particularly medical knowledge and satisfaction of opportunity to contribute to the training of future healthcare professionals. On the other hand, a study that focused on children and adolescents' perspective reported both positive and negative experience. The positive impacts included having fun, develop empathy for peers who had a health condition, financial gain, making new friends, develop an understanding of the difference between 'good' and 'bad' doctors, and gaining important skills for future employment. Meanwhile, negative impacts to the children and adolescent SP were a high commitment to the 'job' leading to tiredness, missing school and declining 


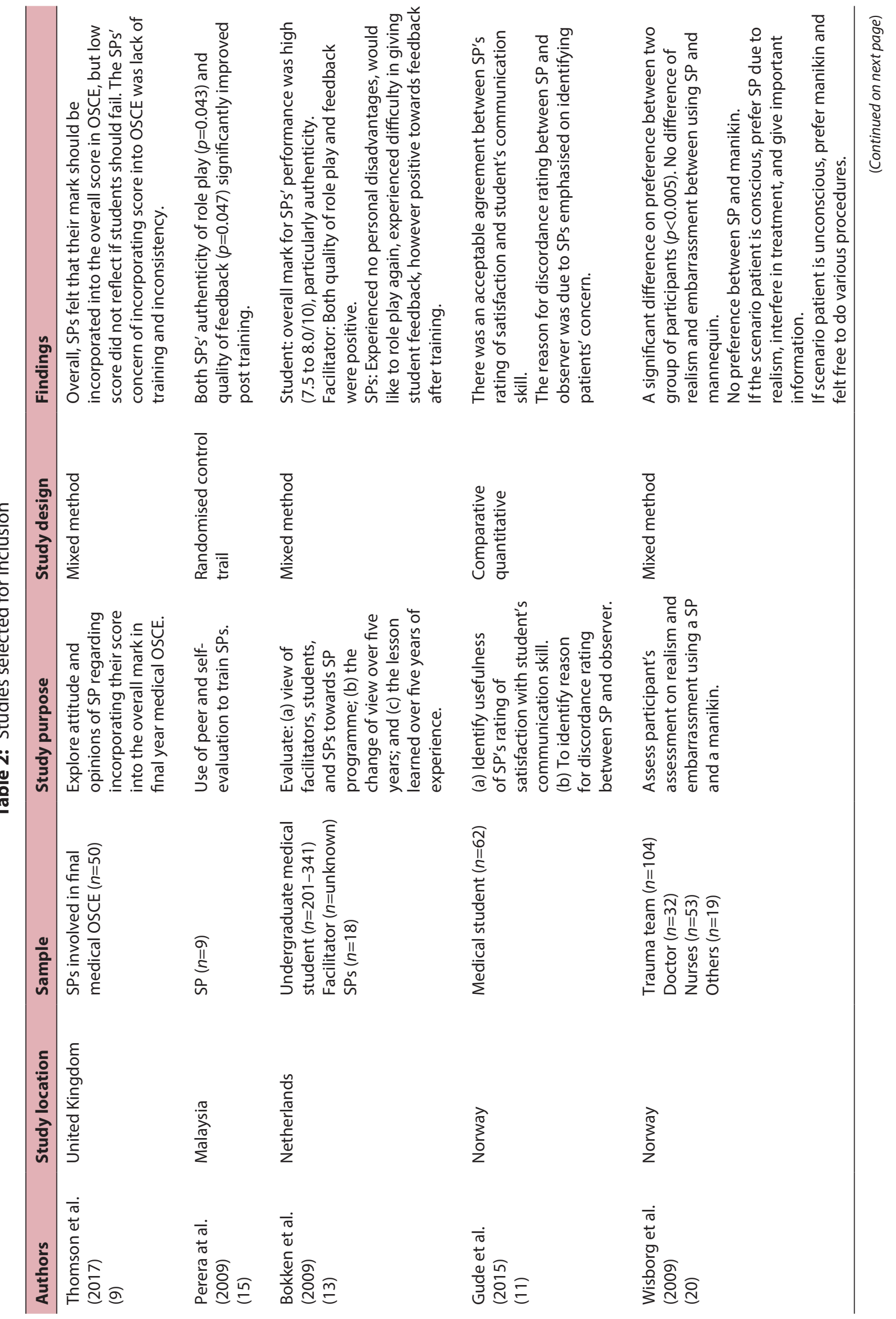




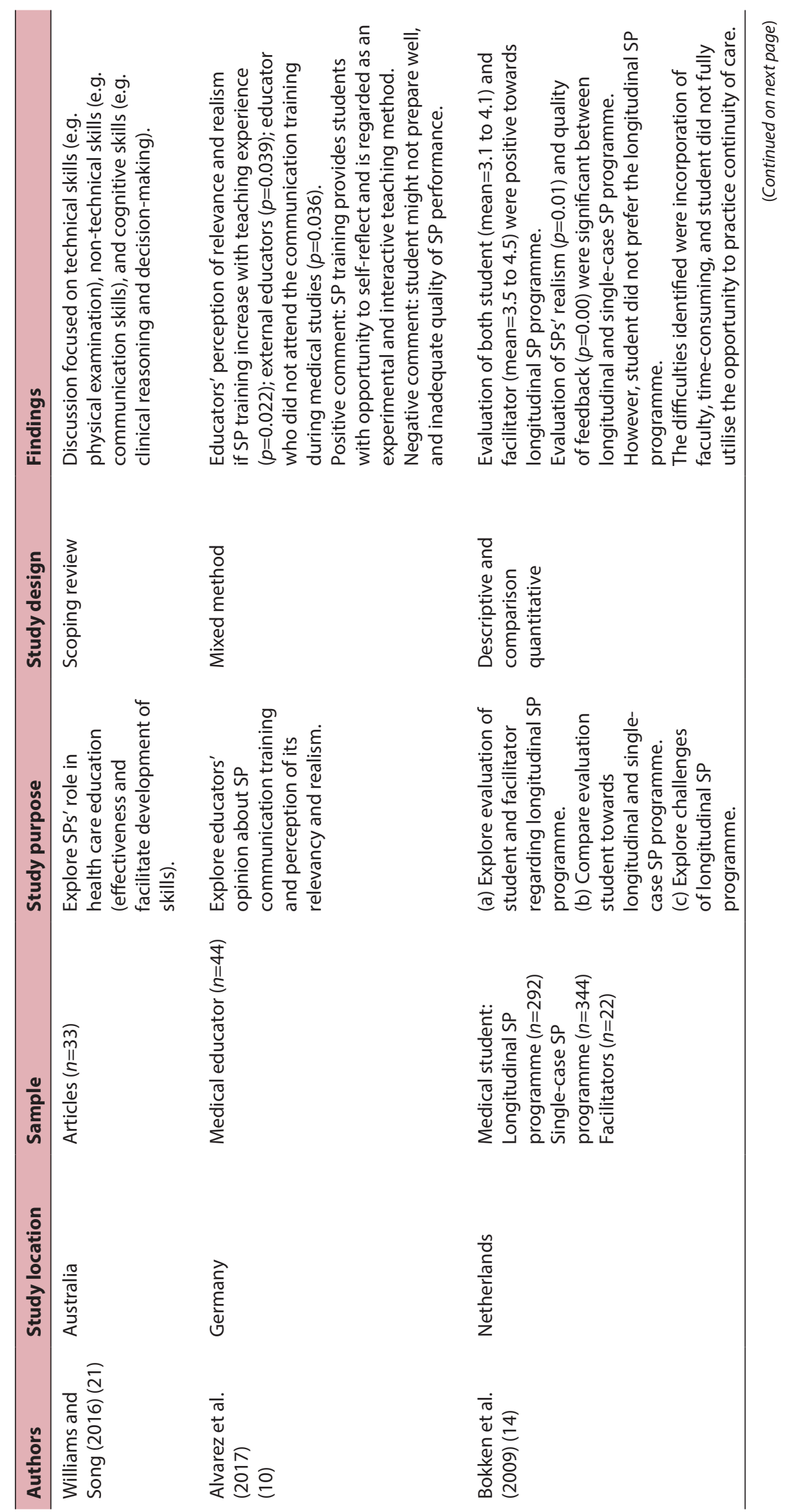




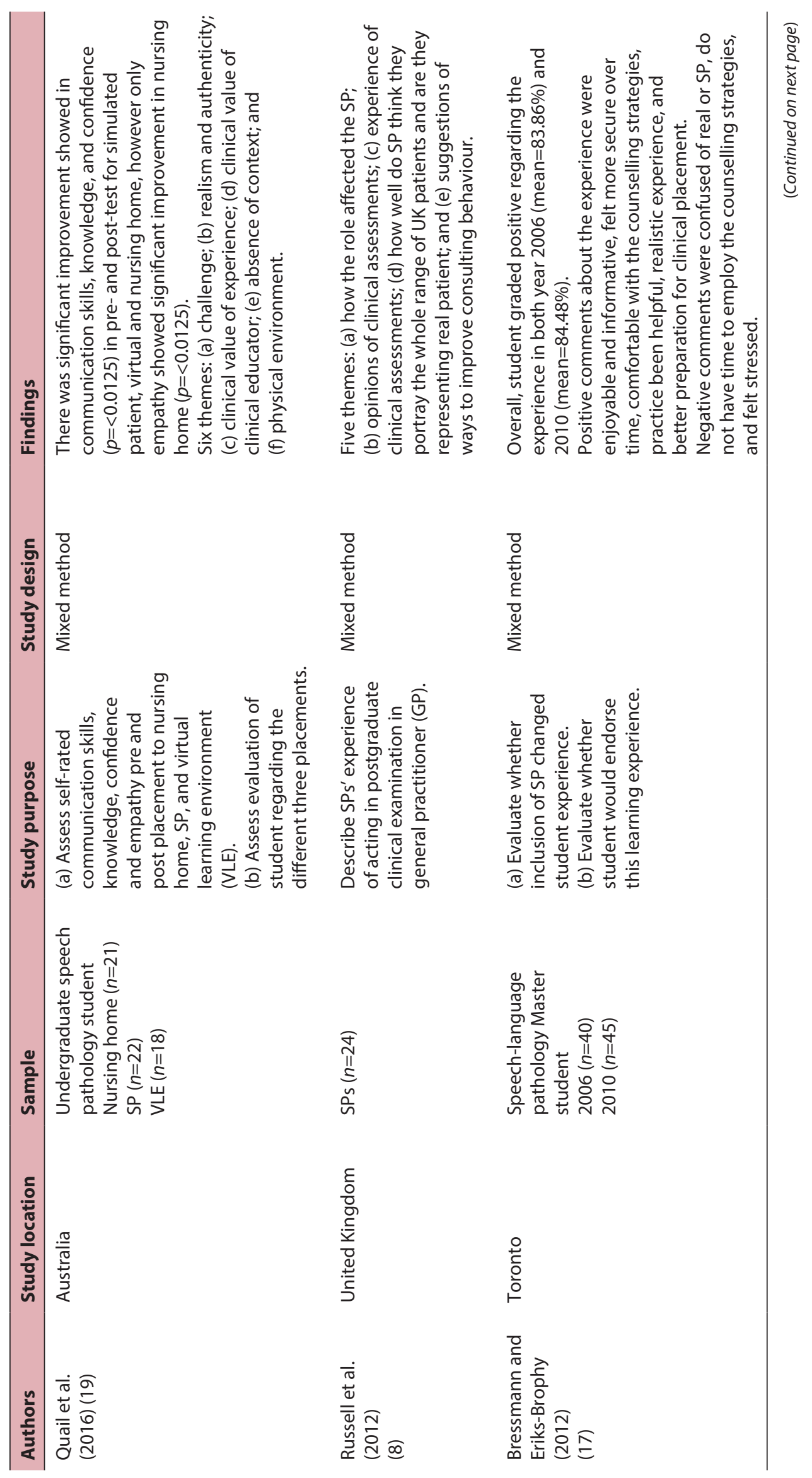




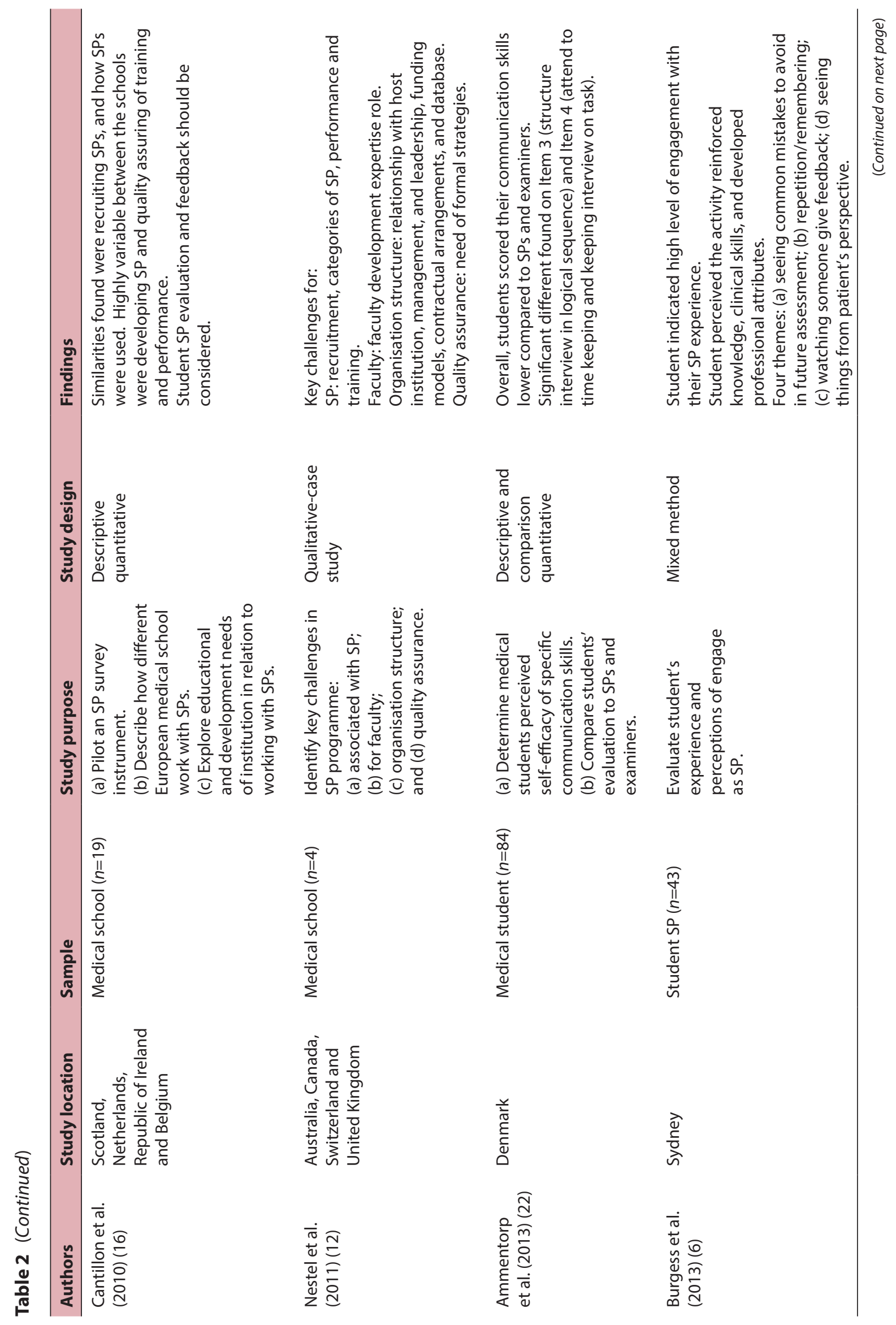


REVIEW | Experience towards Simulated Patient Programme

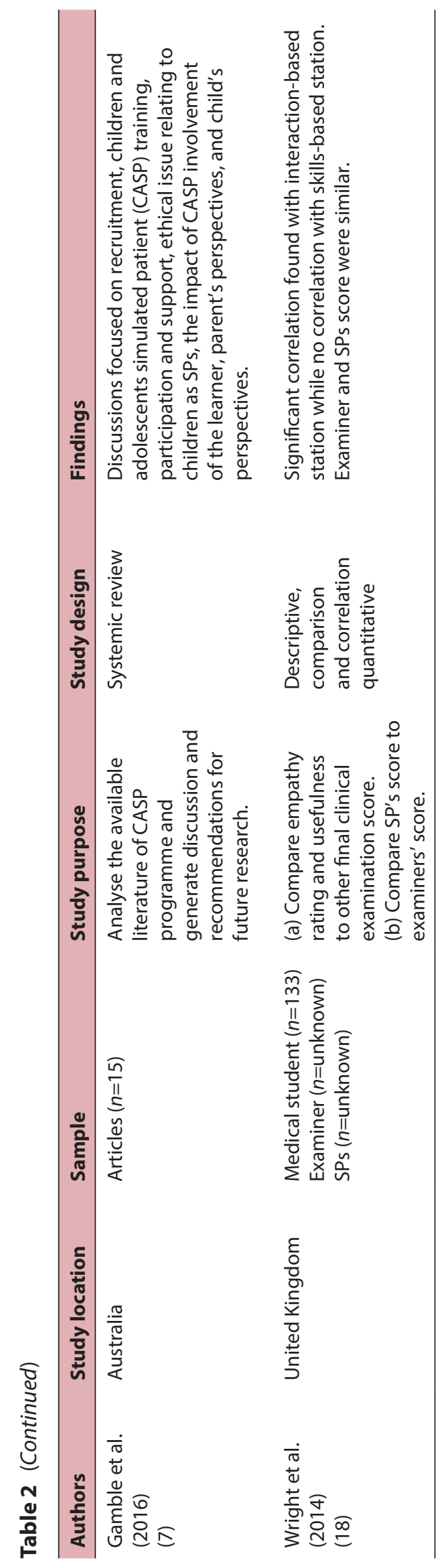


Table 3: Prevalence of themes in articles reviewed

\begin{tabular}{|c|c|c|c|c|c|c|}
\hline \multirow[b]{2}{*}{ Authors } & \multicolumn{6}{|c|}{ Themes } \\
\hline & $\begin{array}{c}\text { SP's } \\
\text { perspective }\end{array}$ & $\begin{array}{l}\text { Evaluation } \\
\text { of SP's } \\
\text { performance }\end{array}$ & $\begin{array}{l}\text { Authenticity } \\
\text { of SP role play }\end{array}$ & $\begin{array}{c}\text { SP } \\
\text { feedback }\end{array}$ & $\begin{array}{c}\text { Student's } \\
\text { development }\end{array}$ & $\begin{array}{l}\text { Evaluation } \\
\text { of student's } \\
\text { performance }\end{array}$ \\
\hline $\begin{array}{l}\text { Thomson et al. } \\
\text { (2017) (9) }\end{array}$ & $\checkmark$ & & & & & $\checkmark$ \\
\hline $\begin{array}{l}\text { Perera et al. (2009) } \\
\text { (15) }\end{array}$ & & $\checkmark$ & & $\checkmark$ & & \\
\hline $\begin{array}{l}\text { Bokken et al. } \\
\text { (2009) (13) }\end{array}$ & & $\checkmark$ & $\checkmark$ & $\checkmark$ & $\checkmark$ & \\
\hline $\begin{array}{l}\text { Gude et al. (2015) } \\
\text { (11) }\end{array}$ & & & & & & $\checkmark$ \\
\hline $\begin{array}{l}\text { Wisborg et al. } \\
(2009)(20)\end{array}$ & & & $\checkmark$ & & & \\
\hline $\begin{array}{l}\text { Williams and Song } \\
(2016)(21)\end{array}$ & & & & & $\checkmark$ & \\
\hline $\begin{array}{l}\text { Alvarez et al. } \\
\text { (2017) (10) }\end{array}$ & & $\checkmark$ & $\checkmark$ & & & \\
\hline $\begin{array}{l}\text { Bokken et al. } \\
\text { (2009) (14) }\end{array}$ & & $\checkmark$ & $\checkmark$ & & $\checkmark$ & \\
\hline $\begin{array}{l}\text { Quail et al. (2016) } \\
\text { (19) }\end{array}$ & & & $\checkmark$ & $\checkmark$ & $\checkmark$ & \\
\hline $\begin{array}{l}\text { Russell et al. } \\
\text { (2012) (8) }\end{array}$ & $\checkmark$ & & $\checkmark$ & & & \\
\hline $\begin{array}{l}\text { Bressmann and } \\
\text { Eriks-Brophy } \\
(2012)(17)\end{array}$ & & & $\checkmark$ & $\checkmark$ & $\checkmark$ & \\
\hline $\begin{array}{l}\text { Cantillon et al. } \\
\text { (2010) (16) }\end{array}$ & & $\checkmark$ & & $\checkmark$ & $\checkmark$ & $\checkmark$ \\
\hline $\begin{array}{l}\text { Nestel et al. (2011) } \\
\text { (12) }\end{array}$ & & $\checkmark$ & $\checkmark$ & $\checkmark$ & $\checkmark$ & \\
\hline $\begin{array}{l}\text { Ammentorp et al. } \\
(2013)(22)\end{array}$ & & & & & & $\checkmark$ \\
\hline $\begin{array}{l}\text { Burgess et al. } \\
\text { (2013) (6) }\end{array}$ & $\checkmark$ & & & & & \\
\hline $\begin{array}{l}\text { Gamble et al. } \\
(2016)(7)\end{array}$ & $\checkmark$ & & $\checkmark$ & $\checkmark$ & $\checkmark$ & \\
\hline $\begin{array}{l}\text { Wright et al. } \\
\text { (2014) (18) }\end{array}$ & & & $\checkmark$ & & & $\checkmark$ \\
\hline
\end{tabular}

school performance, discomfort towards some roles such as consultation involving sexual issue as well as providing feedback to learner often causing anxiety and shock (7). Similar negative effects reported from adult SPs were such as fatigue due to repetition for a long hour (four hours) and anxious to ensure the performance was equivalent to other SPs who played the same role (8). A study focused on medical students' experience who engaged as SP for their junior peer OSCE reported that medical students expressed positively toward SP work. The result showed that participants appreciated SP role as it allowed application and build on the prior knowledge, development of clinical skills, enhancement of confidence in their 
clinical skills, development of own clinical reasoning skills, understand patient-doctor relationship, particularly in understanding the real patients' feelings and problems, increased awareness of ethical, social, and cultural issues. There was no negative impact reported (6). Another study done in the year 2012 reported limited data on SPs' perceived SP work, i.e. SPs considered the task was interesting and challenging (8). An interesting study was done in the year 2017 regarding SP's opinion and attitude towards incorporating SP's score into the summative assessment. Sixty percent of the SPs perceived that their marks should be incorporated into the examination; however, $70 \%$ of SPs emphasised that candidate must at least pass for the lowest SP score. Meanwhile, poor interpersonal skills could be remedied, whereby SPs expressed that they have the responsibility to assess communication skills, attitudes, professionalism, and interpersonal skills. At the same time, SPs were also concerned with consistency among the SPs (9). A few articles also informed regarding SPs' view between 'good' and 'bad' consultation. SPs expressed that 'good' candidates please them, whereas 'poor' candidates upset them. SP perceived that candidates that practiced patient-centred conversation make the future health professional or health care practitioner a 'good' consultant, while poor bedside manner was not acceptable. SPs valued listening actively without interruption, asking appropriate questions in response to SP cues, identify patient's emotional aspects, talking to patient in a natural, focused, and interesting manner, and other non-verbal communication skills (8). However, there was a significant minority of SPs tolerating poor communication skills and interpersonal skills, who justified that medical knowledge and clinical skills were more important than communication skills $(8,10,11)$. The main idea for over-positive rating (SP gave an acceptable score while the observer gave an unacceptable score) as well as over-negative rating (SP gave an unacceptable score while the observer gave an acceptable score) found that identifying patient's concern and attending to patient's emotional aspect were the key elements to ensure patient's satisfaction (11).

\section{Evaluation of SP's performance}

The terminology SP performance in this review was referring to the authenticity of role play and quality of SP feedback. Professional behaviour (e.g. answer call in the middle of OSCE) as part of SP performance (12). Maastricht Assessment of Simulated Patients (MaSP) is commonly used as an instrument to evaluate SP performance (13-15). Meanwhile, video recording and written feedback or scoring were used as strategies to evaluate SP performance $(15,16)$. The assessor can be either student, peer SP, faculty or selfassessment (14-16). SP performance can determine the success of the simulation session and can either destroy or enhance students' motivation in learning. Educators' feedback on quality of SP performance can impact the training session with SP; adequate SP performance can lead to an experiential and interactive session and provide an opportunity for both students and educators to learn something new, while inadequate SP performance can demotivate students (10). Less established SP programmes were less vigorous in their approaches towards SP quality assurance. Each SP programme had informal measure in place to identify under-performing SP, such as informal feedback from faculty $(12,16)$. A study done on an adolescent SP programme in 2009 examined the adolescent SP performance. The overall mark of SP performance was high (from 7.5 to 8.0 on a 10-point scale). The reasons for a decrease by half point over the five-year period may be due to being less strict in the criteria for selection and recruitment process as well as the increase in the number of performances per day (14). Another study that focused on a training approach to enhance SP performance involved students, peer SP, tutor, and self to evaluate the authenticity of role play 
and quality of feedback. Result found significant improvement in the authenticity of role play ( $p=0.043$ ) post training (15). On the other hand, corresponding to SPs' age and personality into the scenario role was also meant to improve SP performance (7). Another study which examined SP performance between longitudinal SP programme and single case SP programme found that the overall SP performance was significantly higher in longitudinal SP programme compared to single case SP programme $(p=0.01$ [authenticity] and $p=0.00$ [feedback]) (14).

\section{Authenticity of SP role play}

A study on using SP to teach students on managing difficult patients found that SP activity had added realism to the learning experience $($ mean $=4.42$ ) while some students even felt stressed and emotionally involved when interacting with the SP (17). When compared between longitudinal SP programme and single case SP programme, students scored SP in the longitudinal programme as more authentic and more like real patient compared to SP in single case programme $(p=0.00)$ (13). However, the validity in assessing candidates' empathy during SP encounter was considered to be not real (18). Few articles found that participants preferred SPs compared to other modalities, for example, a virtual learning environment (VLE) and manikin. Students expressed SPs were more realistic and natural compared to VLE (mean for SP $=4.64$, mean for VLE = 2.42) (19). Another study examined training modalities using manikin and SP and found that participants slightly preferred using SP for training if the patient in the scenario was supposed to be conscious. The participants perceived that interactions with SPs increased the realism of the scenes and was closer to a real clinical situation if the patient was supposed to be active. Additionally, SPs could interfere in the treatment and also give important information. However, participants found SPs to be more restrict to certain procedures, especially invasive procedure and potentially harm the SPs when the engagement was high (20). Several studies indicated that SPs' personal experience potentially enhanced SPs' realistic portrayal of the role. A case study found that scenarios that involved SPs own experience generated a large number of authentic roles in a short period (12). In another study, SPs were asked to choose the decision that came closest to what they would do in reality as well as used SPs' own age and lifestyle when interacting with the student to imitate interview. The outcome was positive on the authenticity of the SP encounter (e.g. mistaken SP as a real patient) (14). A systemic review paper stated that role developed based on SPs' personal experience and inclusive of personal data into the role potentially increased the realism as well as enhanced accuracy and consistency (7). The quality of the scenario and closeness to reality also influenced the authenticity of the character (10). Besides that, SPs expressed that the performance was easy to play when the role involved SPs' personal experience or personal belonging $(7,14)$. However, SPs who performed the role to close to their personality might have difficulty coming out of role (14). On the other hand, the perception of educators on the realism of the scenario was strongly influenced by the preset scenario. The realism may decrease if the scenario given is challenging and difficult to handle (10), for example, confront a patient with incompliance to the treatment and emotionally difficult when informing of terminal illness to SP. When asked from SP's perspective regarding the realistic portrayal of the role, SPs felt that they could reasonably represent real patients as they are in the patient's shoe and could in a realistic way respond to students' questions. SPs expressed that students should be able to enter into the role play if everything was apparently real. Students who were unable to play the role as real consultant influenced SP's performance as they struggled to keep a realistic portrayal of the case (8). 


\section{SP feedback}

Good evidence indicated that SP-provided student feedback served benefits for educational purpose (16). SP feedback especially children and adolescent SPs was powerful in evaluating students' performance, supported students' improvement as well as resulted in powerful learning outcomes (7). Studies suggested that students learned from SP feedback by reflection process (17, 19). Students valued and demanded for detailed feedback from SP $(14,17)$ and commented that the shortcoming of the learning experience with SP was the lack of feedback from SPs. On the other hand, SP perceived providing feedback to students was difficult, felt uneasy, troublesome, and at times anxiety provoking $(7,14)$. SP feedback can be given immediately after the role-play or videotaped for later review by the trainee (12). SP feedback can be given either in their role-playing person or as themselves and SPs expressed that they preferred to feedback in their real person, rather than in 'role' (7). Training SP for providing feedback plays an essential role in improving SPs' feedback skills and change perception of provided SP feedback $(7,14,15)$. Result found significant improvement in the quality of feedback ( $p=0.047$ ) post-training (15). A study showed that adolescent SPs were more positive towards feedback over the past four years. On the other hand, the facilitators commented positively towards SPs' feedback, for example, 'very natural' and 'more direct feedback' (14).

\section{Student's development}

Research had confirmed that training sessions with SPs enabled medical students to reinforce knowledge, develop communication skills, enhance clinical skills as well as cognitive aspect of clinical competence such as decision-making and clinical reasoning, practice interviewing skills, increase awareness of ethics, and enhance confidence $(7,19-21)$. Studies have reported medical schools in Ireland,
Scotland, Belgium, Netherlands, Australia, Canada, Switzerland, and United Kingdom using SPs to train medical students in communication skills and physical examination skills. Majority of the medical schools emphasised on the integration of physical examination and communication skills. 'Hybrid simulation' further enhanced the development of clinical skills with an emphasis on communication competence. Hybrid simulation is regarded as a method that integrates SPs and mannequins (21), for example, using an SP and an arm model to teach, practice or assess both clinical skills and communication skills. A comparison study was done in 2012 by on the speech-language pathology students' learning experience about managing difficult patients using SP methodology and group presentation and role play. The quantitative result found that there were no significant differences between two group of students' grades of the learning experience, thus, did not conclude that SP methodology contributes more experience in speechlanguage pathology students' learning. However, quantitative data showed that student appreciated the opportunities to try the Six Category Intervention Analysis strategies with SP and expressed that the interaction with SP added interest to the learning experience (17). Another study on an SP programme involved adolescent as SP in teaching medical students on communicating sensitive consultation such as contraceptive and sexuality issue. The facilitators remarked that involving adolescent SP addressed an interesting aspect of communication, for example, dealing with peers professionally and asking questions about or discussing sexuality (14). Both studies indicated that SP methodology improves the students' learning experience. Another comparison study on longitudinal SP programme and single case SP programme showed that students were neutral about learning communication skills from both SP methodology (13). A systemic review of children and adolescents simulated patient paper concluded that SPs had impacted all health care education 
programmes positively on confidence (7). Another study supported that involvement of SPs increased student's confidence. The result of the study showed that undergraduate speech pathology students self-perceived that the confidence level had significantly increased post interaction with SP for a week (19). However, training with SP may develop an unrealistic feeling of confidence, pertaining to the scenario when student can manage a difficult SP (17).

\section{Evaluation of students' performance}

SP is regarded as an expert to comment upon students' certain aspects such as communication skills $(9,16)$ and empathy (18) due to SPs are directly in the clinical encounter and therefore likely to be in a position to assess such skills $(9,18)$ as well as the institution acknowledge the ability of SPs to effectively assess trainees' communication skills and interpersonal skills (9). Few studies had confirmed the reliability and validity of SP's evaluation. For example, research done in the year 2015 examined the SPs' score for satisfaction and observers (medical students) scored for their peers' communication skills. To keep the SPs as close as possible to the experience of a real patient, SPs were not trained or instructed on how to evaluate the trainee's performance. The findings showed $74 \%$ agreement on the acceptable score for communication by observers and satisfactory score by SPs, while $71 \%$ agreement on the unacceptable score for communication by observers and unsatisfactory score by SPs. Thus, the study concluded that the SPs' score of satisfaction can be useful to evaluate medical trainees' communication skills (11). Another comparison study examined both SPs and observers (clinical tutors) rate on medical students' empathy. Both observers and SPs were trained prior to the examination on how to use the scoring templet. The findings showed that the SPs and the observers' rate were very similar (SP mean score $=$ 3.64; examiner mean score $=3.69$ ). This study concluded SP can rate empathy and found inter-rater correlation was reasonably good compared to clinical tutor (18). Another study done in the year 2013 examined evaluation of observers (medical doctors), SPs, and medical students (selfevaluation) towards communication skills. However, training or instruction prior to the evaluation was not mentioned in the study. The result indicated a high agreement between the evaluation of the performance of different items by the students, patients, and observers. Both SPs and observers scored significantly higher than students. When analysing the questionnaire individually, Item 3 (structured interview in a logical sequence) and Item 4 (attend to timekeeping and keeping the interview on task) were found to be scored less by students when compared to observers and SPs (22).

\section{DISCUSSION}

Several key themes emerged from this review of the relationship between the SPs, students, and facilitators. Firstly, SP methodology has been widely used to train healthcare students in the development of medical knowledge, clinical skills, as well as important soft skills such as empathy, communication skills, and confidence. One simulation session can train both SP and student and mostly through reflection. SP can develop medical knowledge, especially the signs and symptoms of illnesses, how a consultation is expected to be done, medications, treatments, and so on during the facilitators lecturing the students. Meanwhile, students have been given opportunities to integrate their knowledge into a scenario, practice their clinical skills and communication skills with SP as well as apply clinical reasoning, critical thinking, interpersonal skills, etc. SP feedback was another powerful tool to enhance students' learning experience. SP feedback gave opportunities for the students to reflect and learn their strength and weakness from the direct encounter. There is one study that mentioned educators sometimes might learn 
new things from the SP (10), however, the specificity of the learning was not further explored. Thus, further research which will examine the development of the lecturer aspect is needed.

Secondly, all three parties, SPs, students, and facilitators, played a part to achieve the success of a simulation session. In detail, SP who can portray the role realistically managed to engage students emotionally. The student also must be able to play the role well to keep realistic the portrayal. Lecturer plays a part in the case development as the scenario must be as close as possible to reality and integration of some of the SP's details such as (age and lifestyle) can increase the realism of the role portrayal. If the SP is unable to portray as close as a real patient by authentically responding to the student's question, the student's learning experience will be spoilt. For example, in the middle of the interview session, SP responding that the answer is not stated in the script. Likewise, the student who could not role play as a real consultant demotivated the SP who had spent time and effort preparing to portray a real patient. For example, the student did not keep eye contact with SP who is discussing an imitate issue such as infertility. Meanwhile, the lecturer who prepares and expect SP to memorise three pages of scripts and demand accuracy of every single detail in the script might decrease the realistic portrayal of the role. SP was focusing on giving every single detail that did not belong to themselves, including the name, which less focused on portraying the emotional and psychosocial aspect of the role.

Thirdly, the outcome of the training with SP was examined through an assessment of the student's performance or SP's performance. SPs, peer students, and lecturers, and even self-evaluation have been done to evaluate for the trainees' soft skills, especially communication skills. SP has been regarded as a valid tool to rate students' performance. Due to the direct encounter with a student, SPs were in the most appropriate position to score students and studies confirmed that the SP mark was similar to the mark given by the clinical expert. SPs have been mostly assessed for their authenticity of the role portrayal and quality of feedback using a checklist by both lecturers and students. However, a formal, feasible, and sustainable process to ensure the quality assurance of SP's performance is yet to be discovered. The reason might be limited knowledge on the SP methodology as well as quality assurance, manpower issue, and lack of strategies to monitor every single SP in the programme. Educators were examined on both SP's and student's performances, but lecturer's performance was not discovered in this review.

The outcome of the review of experience towards SP-based simulation session concluded that SPs' development indirectly influences students' development. SPs developed their portrayal skills and feedback skills through training and evaluation, thus enhanced medical and health profession's trainees in skills development through the student-SP encounter as well as constructive feedback and/or assessment from the SP. This review recommended that structured training and structured quality assurance to be integrated into the SP programme to ensure better student outcome.

\section{REFERENCES}

1. Beigzadeh A, Bahmanbijari B, Sharifpoor E, Rahimi M. Standardized patients versus simulated patients in medical education: are they the same or different. Journal of Emergency Practice and Trauma. 2016;2(1):25-8. https://doi.org/10.15171/ jept. 2015.05

2. Nestal D, Bearman $M$. Introduction to simulated patient methodology. In: Nestel D, Bearman M, editors. Simulated patient methodology: theory, evidence and practice. United Kingdom: John Wiley \& Sons Ltd; 2015. p. 1-4. https://doi. org/10.1002/9781118760673.ch1 
3. Onari MJ, Pampaloni F, Multak N. What is a standardized patient? In: Wilson L, Rockstraw L, editors. Human simulation for nursing and health professions. United States: Springer Publishing Company; 2012.

4. Nestel D, Morrison T, Pritchard S. Scope of contemporary simulated patient methodology. In: Nestel D, Bearman M, editors. Simulated patient methodology: theory, evidence and practice. United Kingdom: John Wiley \& Sons Ltd; 2015. p. 7-15. https://doi. org/10.1002/9781118760673.ch2

5. Thistlethwaite JE, Ridgway GD. The content and process of simulated patientbased learning activities. In: Nestel D, Bearman M, editors. Simulated patient methodology: theory, evidence and practice. United Kingdom: John Wiley \& Sons Ltd; 2015. p. 16-22. https://doi. org/10.1002/9781118760673.ch3

6. Burgess A, Clark T, Chapman R, Mellis C. Medical student experience as simulated patients in the OSCE. Clin Teach. 2013;10(4):246-50. https://doi.org/10.1111/ tct. 12016

7. Gamble A, Bearman M, Nestel D. A systematic review: children and adolescents as simulated patients in health professional education. BMC Advances in Simulation. 2016;1(1): 1-16. https://doi.org/10.1186/ s41077-015-0003-9

8. Russell D, Etherington C, Hawthorne K. How can simulated patients' experiences suggest ways to improve candidate performance in the MRCGP clinical assessments? Education for Primary Care. 2012;23(6):391-98. https://doi.org/10.1080/ 14739879.2012 .11494150

9. Thomson FC, MacKenzie RK, Anderson M, Denison AR, Currie GP. Incorporating patient partner scores into high stakes assessment: an observational study into opinions and attitudes. BMC Med Educ. 2017;17(214):1-7. https://doi.org/10.1186/ s12909-017-1063-4
10. Alvarez S, Schultz J. Medical educators' perception of communication training with simulated patients: an explorative study approach. BMC Res Notes. 2017;10(650):1-5. https://doi.org/10.1186/ s13104-017-2988-8

11. Gude T, Grimstad H, Holen A, Anvik T, Baerheim A, Fasmer OB, et al. Can we rely on simulated patients' satisfaction with their consultation for assessing medical students' communication skills? A cross-sectional study. BMC Med Educ. 2015;15(226):1-6. https://doi.org/10.1186/1757-7241-17-59

12. Nestel D, Tabak D, Tierney T, LayatBurn C, Robb A, Clark S, et al. Key challenges in simulated patient programs: an international comparative case study. BMC Med Educ. 2011;11(69):2-10. https://doi. org/10.1186/1472-6920-11-69

13. Bokken L, Dalen JV, Scherpbier A, Vleuten CVD, Rethans J. Lessons learned from an adolescent simulated patient educational program: five years of experience. Med Teach. 2009;31(1):605-12. https://doi. org/10.1080/01421590802208891

14. Bokken L, Linssen T, Scherpbier A, Veluten C, Rethans J. The longitudinal simulated patient program: evaluations by teachers and students and feasibility. Med Teach. 2009;31(1):613-20. https://doi. org/10.1080/01421590802334283

15. Perera J, Perea J, Abdullah J, Lee N. Training simulated patients: evaluation of a training approach using self-assessment and peer/tutor feedback to improve performance. BMC Med Educ. 2009;9(37):1-6. https:// doi.org/10.1186/1472-6920-9-37

16. Cantillon P, Stewart B, Haeck K, Bills J, Ker J, Rethans J. Simulated patient programmes in Europe: collegiality or separate development? Med Teach. 2010;32(3):106-10. https://doi.org/10.3109/ 01421590903389090 
17. Bressmann T, Eriks-Brophy A. Use of simulated patients for a student learning experience on managing difficult behaviour in speech-language pathology contexts. Int J Speech Lang Pathol. 2012;14(2):165-73. https://doi.org/10.3109/17549507.2011.638 727

18. Wright $\mathrm{B}$, McKendree J, Morgan L, Allgar VL, Brown A. Examiner and simulated patient ratings of empathy in medical student final year clinical examination: are they useful? BMC Med Educ. 2014;14(199):1-8. https://doi. org/10.1186/1472-6920-14-199

19. Quail M, Brundage SB, Spitalnick J, Allen PJ, Beilby J. Student self-reported communication skill, knowledge and confidence across standardized patient, virtual and traditional clinical learning environments. BMC Med Educ. 2016;16(73):1-12. https://doi.org/10.1186/ s12909-016-0577-5
20. Wisborg T, Guttorm B, BrinchmannHansen A, Hansen KS. Mannequin or standardized patient: participants' assessment of two training modalities in trauma team simulation. Scand J Trauma Resusc Emerg Med. 2009;17(59):1-4. https://doi.org/10.1186/1757-7241-17-59

21. Williams B, Song JJY. Are simulated patient effective in facilitating development of clinical competence for healthcare students? A scoping review. BMC Advances in Simulation. 2016;1(6):1-9. https://doi. org/10.1186/s41077-016-0006-1

22. Ammentorp J, Thomsen JL, Jarbol DE, Holst R, Ovrehus ALH, Kofoed PE. Comparison of the medical students' perceived self-efficacy and the evaluation of the observers and patients. BMC Med Educ. 2013;13(49):1-6. https://doi. org/10.1186/1472-6920-13-49 